(Large Eddy Simulation の試み)

$$
\begin{aligned}
& \text { 松 崎 和 愛*1, 工 藤 康 } \text { 人 }^{* 2} \\
& \text { 大 庭 英 樹*1, 宗 像 瑞 恵 }{ }^{* 1}
\end{aligned}
$$

\title{
A Study on Swirling Flows in a Cyclone Separator (Application of Large Eddy Simulation)
}

\author{
Kazuyoshi MATSUZAKI*3, Yasuhito KUDO, \\ Hideki OHBA and Mizue MUNEKATA \\ ${ }^{* 3}$ Department of Mechanical Engineering and Materials Science, Kumamoto University, \\ 2-39-1 Kurokami, Kumamoto-shi, Kumamoto, 860-8555 Japan
}

\begin{abstract}
Numerical simulation of the swirling flows in a cyclone separator is performed using a large eddy simulation (LES) based on a Smagorinsky model. The validity of the simulation and the complicated flow characteristics are discussed by comparison with experimental results. Moreover, particle motions are treated by a Lagragian method and are calculated with a one-way method. A performance for particle separation is predicted from the results of the particle tracing. As results of our investigation, it is found that the LES has sufficient accuracy to predict the complicated swirling flows in the cyclone separator.
\end{abstract}

Key Words: Swirling Flow, Cyclone Separator, Large Eddy Simulation, Particle Motion, Numerical Analysis

\section{1. 緒論}

サイクロン分離器は, 旋回流による遠心力を利用 し粒子の分離を行う装置であり, 除㢈装置, 粉体材料 の製造プロセスなど，幅広く利用されている．しかし ながら，その粒子分離性能は，近年の粉体材料の粒子 設計で要求される分離精度に対して不十分である.し たがって，従来の比較的大きな粒子の分離に基づいた 設計法ではその要求を満足するのは難しいため, 高精 度の粒子分離可能な新型のサイクロン分離器を開発す ることが望まれている. そのためには，小さな粒子の 運動は，流れの乱れに大きく影響されると考えられる ので, サイクロン分離器内の複雑な旋回流れの乱流構 造と粒子運動の関係を明らかにすることが重要である.

そこで, 著者らは新しいタイプの接線形のサイク ロン分離器(1)について, その構造を簡単化したサイ クロンモデルを用いて，その内部の旋回流れ構造と粒 子運動の関連性について実験的に調查してきた ${ }^{(1)}$ ( (3). 本報告は，その複雑な旋回流れ場の数值解析に関寸る ものである. 過去の研究において, サイクロン分離器

$*$ 原稿受付 2004 年 1 月 26 日.

*1 正員, 熊本大学工学部 ( $\mathbf{\$} 860-8555$ 熊本市黒髪 2-39-1).

*2 熊本大学大学院自然科学研究科.

E-mail :mzaki@gpo.kumamoto-u.ac.jp
内旋回流れに対しレイノルズ平均に基づく数値解析 (RANS) が適用されてきた ${ }^{(4),(5)}$. しかしながら， これらのシミュレーションでは, 時間平均モデルであ るため渦心の振九回り, 渦崩壊現象のような旋回流れ 特有の非定常現象を予測することは困難であると考え られる. また，RANSにおいて幅広く利用されている 標淮的な $k \cdot \varepsilon$ モデルでは, 旋回流の平均流れ特性を 正確に予測できないことも知られている(6).

したがって, 本研究では近年注目されている Large Eddy Simulation（LES）を複雑なサイク ロン分離器内旋回流れに適用し, 著者らによる実験結 果との比較を通し，本解析の有効性を検討した. また, 個々の粒子をラグランジュ的に取り扱い，流体から粒 子一の影響のみを考虑した Oneway method を用い て粒子追跡を行い, サイクロン分離器の粒子分離性能 の数值的予測を試みた.

\section{2 おもな記号}

$A:$ 粒子の投影面積 $\left(=\pi d_{p}{ }^{2} / 4\right)$

$C_{1}, C_{2}, C_{3}$ : 粒子に働く粘性トルクに関する定数

$C_{D}$ : 抗力係数

$C_{I R}$ : 揚力係数

$C_{T}$ : 無次元定数 
$C_{s}:$ スマゴリンスキー定数 $(0.1)$

$d_{p}:$ 粒子の直径 $(5,10 \mu \mathrm{m})$

$D / D t:$ 実質微分

$g:$ 重力加速度 $\left(9.81 \mathrm{~m} / \mathrm{s}^{2}\right)$

$H$ : サイクロン旋回室高さ $(340 \mathrm{~mm})$

$I:$ 粒子の慣性モーメント $\left(=\pi \rho_{p} d_{p}^{5} / 60\right)$

$m:$ 質量

$r, \theta, z:$ 円筒座標系

$q_{r}:$ 半径方向の Flux $\left(=r \times v_{r}\right)$

$r_{\mathrm{o}}$ : サイクロン流出管半径

$R$ : サイクロン旋回室半径 $(72 \mathrm{~mm})$

$R e_{p}:$ 粒子レイノルズ数 $\left(=d_{p}\left\|u_{R}\right\| / v\right)$

$R e_{R}:$ 粒子の回転レイノルス数 $\left(=d_{p}\left\|\omega_{R}\right\| / 4 v\right)$

$T:$ 無次元時間

$u_{i}: x, y, z$ 方向速度成分 $(i=1,2,3)$

$V_{n}:$ 断面平均流入速度 $(7.8 \mathrm{~m} / \mathrm{s})$

$V_{r}, v_{\theta}, v_{z}: r, \theta, z$ 方向の速度成分

$x_{i}: x, y, z$ 座標 $(i=1,2,3)$

$\eta:$ 粒子の捕集率

$\Delta t:$ 無次元時間刻み

$\mu_{f}:$ 流体の粘度 $\left(18.22 \times 10^{-6} \mathrm{~Pa} \cdot \mathrm{s}\right)$

$v:$ 流体の動粘度 $\left(15.12 \times 10^{-6} \mathrm{~m}^{2} / \mathrm{s}\right)$

$\rho:$ 密度

$\omega:$ 回転角速度

添字

$f:$ 流体の物理量を示寸

$n:$ 時刻を示寸

$p:$ 粒子の物理量を示寸

$R:$ 流体の粒子に対する相対量を示寸

\section{3. 数値解析法}

$3 \cdot 1$ サイクロン分部器モデル 図 1 に本研究の 計算対象であるサイクロン分離器モデルの概略図を示 す。これは，著者らが実験で使用したサイクロンモデ ル $^{(3)}$ とほほ同じである. このモデルは半径 $R 72 \mathrm{~mm}$,

高さH $340 \mathrm{~mm}$ の旋回室を持ち, 気流は旋回室の上部 より接線方向に流入し，旋回室の下部に同軸上に設置 された半径 $r_{o} 43.2 \mathrm{~mm}(0.6 R)$ の流出管より流出寸る. 図 1 に示寸ように, 旋回室内の旋回流れに及ぼす流出 管位置の影響を調查するために，流出管を旋回室底部 に取り付けた場合（TYPE-A）および底部より $85 \mathrm{~mm}$ $(0.25 H)$ 内側一挿入した場合 (TYPE-B) の 2 種類の 計算を行った. 流出管の長さは, TYPE-A の場合 680 $\mathrm{mm}(2 H)$ ，TYPE-B の場合 $765 \mathrm{~mm}(2.25 H)$ とした.

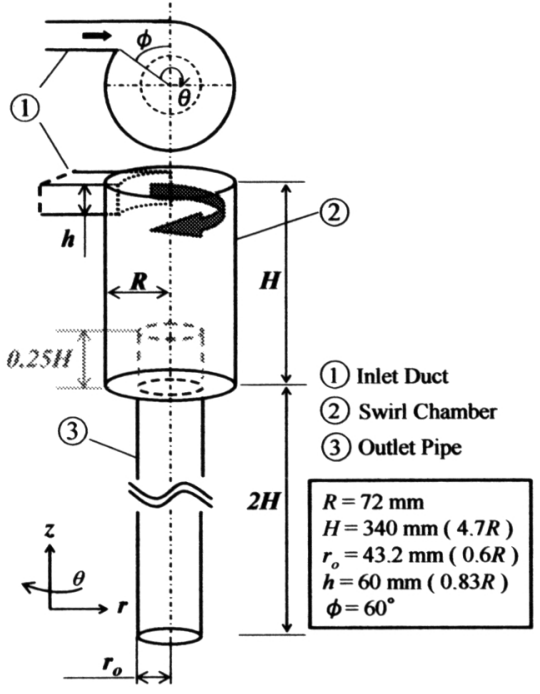

Fig.1 Schematic view of the cyclone separator

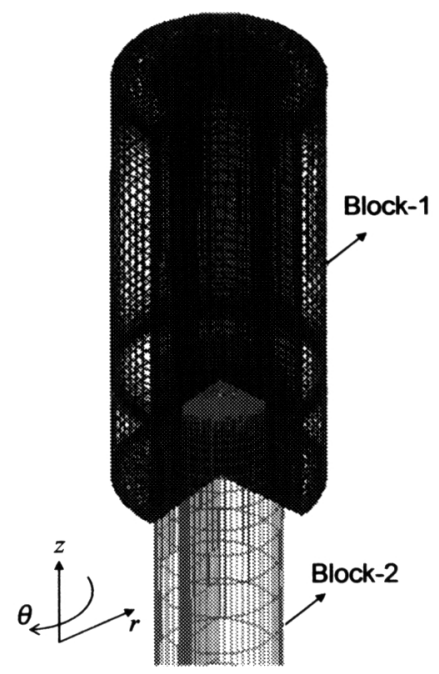

Fig.2 The computational grid for TYPE-B

平均流入速度 $V_{\boldsymbol{n}}$ （流入流量を流入ダクトの断面積で 除して算出した速度）は著者らの実験と同様 $7.8 \mathrm{~m} / \mathrm{s}$ とし, 旋回室半径および平均流入速度に基づくレイ ノルズ数は実験と同様 37,000 とした. 図 1 に示寸よ うに円筒座標系が採用され，座標原点は旋回室底面の 中心設定した.

3-2 Large Eddy Simulation 本研究にお ける LES の基礎式は, 円筒座標系で記述され，空間 フィルターを施された非圧縮粘性流体の連続の式と Navier-Stokes 方程式である. 支配方程式の離散化は 有限差分法が用いられ，特異点での離散化を容易にす 
るため, 半径方向の Flux $q_{r}=r \times v_{r}\left(v_{r}\right.$ は半径方向速 度) が変数として導入された ${ }^{(7)}$. 速度と圧力のカップ リングには Fractional Step 法が用いられた. Subgrid Scale (SGS) 応力のモデル化には Smagorinsky モデル(8) が採用され，その壁面近傍の堿衰には van Driest 型の damping 関数が用いられた. 本計算では Smagorinsky 定数 $C_{s}$ を 0.1 とした. 本研究で用いた計 算コードは, 基本的には円筒座標系の DNS (Direct Numerical Simulation) のコード(9)に SGS 応力項の部 分を付加したものである. ただし，計算の安定のため 対流項には 3 次精度修正上流差分法 ${ }^{(10)}$ が適用された。 その他の空間項は 2 次精度中心差分が用いられた. 時 間積分には，対流項およひ浻粘性を含む項には 3 次精 度 Adams-Bashforth 法, 粘性項には 2次精度 CrankNicolson 法が適用された。

変数配置には Staggered Grid System が用いられた. $r, z$ 方向の格子は，双曲型の関数を用いて壁面近傍で 密になるように生成され， $\theta$ 方向には等間隔格子が用 いられた.

$3 \cdot 3$ 粒子正动 微小な棡体球の運動は, 以下に 示す並進運動と回転運動の方程式で記述される ${ }^{(1),}$ (12).

$$
\begin{aligned}
m_{p} \frac{d u_{p i}}{d t} & =\frac{1}{2} \rho_{f}\left\|u_{R}\right\| A\left(C_{D} u_{R i}+C_{L R} \frac{\left(u_{R} \times \omega_{R}\right)_{i}}{\left\|\omega_{R}\right\|}\right) \\
& +1.61 d_{p}^{2} \sqrt{\mu_{f} \rho_{f}} \frac{\left(u_{R} \times \omega_{f}\right)_{i}}{\sqrt{\left\|\omega_{f}\right\|}} \\
& +m_{f} \frac{D u_{f i}}{D t}+\frac{1}{2} m_{f}\left(\frac{D u_{f i}}{D t}-\frac{d u_{p i}}{d t}\right) \\
& +\left(m_{p}-m_{f}\right) g \delta_{i 3} \\
I \frac{d \omega_{p i}}{d t} & =-C_{T} \frac{1}{2} \rho_{f}\left(\frac{d_{p}}{2}\right)^{5}\left\|\omega_{R}\right\| \omega_{R i}
\end{aligned}
$$

式（1）の右辺第 1 項は抗力，第 2 項は回転運動によ る揚力, 第 3 項は Saffman 揚力, 第 4 項は流体の圧 カこう配およひ粘性応力による力，第 5 項は仮想質量 項, 最終項は浮力 (重力) 項を示寸. 抗力係数 $C_{D}$, 揚力俰数 $C_{L R}$ はそれぞれ以下の式で与えた.

$C_{D}=\frac{24}{R e_{p}}\left(1+0.15 R e_{p}^{0.687}\right)$

$C_{L R}=\min \left[0.5,0.25 \frac{d_{p}\left\|\omega_{R}\right\|}{\left\|u_{R}\right\|}\right]$

ここで, $R e_{p}$ は粒子レイノルズ数である. 式 (2) の右 辺は粒子の回転に対する粘性トルクである. $C_{T}$ は無 次元定数であり, 以下の回転レイノルズ数 $R e_{R}$ の関数
Table 1 Coefficients for equation (5)

\begin{tabular}{|c|c|c|c|}
\hline $\operatorname{Re}_{\boldsymbol{R}}$ & $\boldsymbol{C}_{\mathbf{1}}$ & $\boldsymbol{C}_{\mathbf{2}}$ & $\boldsymbol{C}_{\mathbf{3}}$ \\
\hline $0-1$ & 0 & $16 \pi$ & 0 \\
\hline $1-10$ & 0 & $16 \pi$ & 0.0418 \\
\hline $10-20$ & 5.32 & 37.2 & 0 \\
\hline $20-50$ & 6.44 & 37.2 & 0 \\
\hline $50-100$ & 6.45 & 32.1 & 0 \\
\hline
\end{tabular}

Table 2 Particle properties used in this study

\begin{tabular}{|c|c|c|}
\hline Material & \multicolumn{2}{c|}{ Lycopodium } \\
\hline p-p collisions & \multicolumn{2}{|c|}{ Without } \\
\hline The number of particles & \multicolumn{2}{|c|}{100,000} \\
\hline$\rho_{p}\left[\mathrm{~kg} / \mathrm{m}^{3}\right]$ & \multicolumn{2}{|c|}{700} \\
\hline$d_{p}[\mu \mathrm{m}]$ & 5 & 10 \\
\hline Relaxation time [ ms ] & 0.053 & 0.21 \\
\hline Volume fraction [ $\left.\times 10^{-9}\right]$ & 1.18 & 9.46 \\
\hline Loading ratio [ $\left.\times 10^{-6}\right]$ & 0.687 & 5.49 \\
\hline Coefficient of restitution & \multicolumn{2}{|c|}{0.95} \\
\hline Coefficient of friction & \multicolumn{2}{|c|}{0.3} \\
\hline
\end{tabular}

として表される(13).

$C_{T}=\frac{C_{1}}{R e_{R}^{1 / 2}}+\frac{C_{2}}{R e_{R}}+C_{3}$

ここで, $C_{1}, C_{2}, C_{3}$ は $R_{R}$ の範囲により決まる定数で あり，表1にその值を示す。

粒子位置での流体速度は，粒子が存在するセルの 8 点の線形補間で計算され，式 (1)，（2）の時間積分 には 3 次精度 Adams-Bashforth 法が適用され，粒子 位置は以下に示寸 2 次精度の Crank-Nicolson 法によ り決定された。

$x_{i}^{n+1}=x_{i}^{n}+\frac{\Delta t}{2}\left(u_{p i}^{n+1}+u_{p i}^{n}\right)$

$3 \cdot 4$ 計算条件および境界条件 図2に TYPE-B における計算格子図を示す，図に示すように，計算領 域は 2 つ計算ブロックから成り, Block-1 は旋回室 の計算領域であり，その格子数は, TYPE-A では $r, \theta$, $z$ 方向にそれぞれ $64 \times 65 \times 64 ，$ TYPE-B では $64 \times 65 \times$ 84設けた. Block-2 は流出管の計算領域であり, その 格子数は TYPE-A, B ともに $32 \times 65 \times 64$ 設けた. こ れらの格子数は, 周方向および $z$ 方向に 2 倍の格子数

(TYPE-A :64 × $129 \times 128$, TYPE-B : $64 \times 129 \times 168$, Block-2 は周方向のみ 2 倍) での計算結果と比較検討 し，定性的に差がないことを確認した上で，計算時間 の都合により決定された. 無次元時間刻み $\Delta t$ は, TYPE-A, B それぞれ $5 \times 10^{-4}, 4 \times 10^{-4}$ とした. 平均流 れ場は，流れが十分発達したと思われるところから無 次元時間 100 の時間平均より求めた。境界条件は，壁 面で速度に滑り無し条件, 圧力にノイマン条件を課し た. 流入境界にはサイクロン旋回室接的方向に一様流 


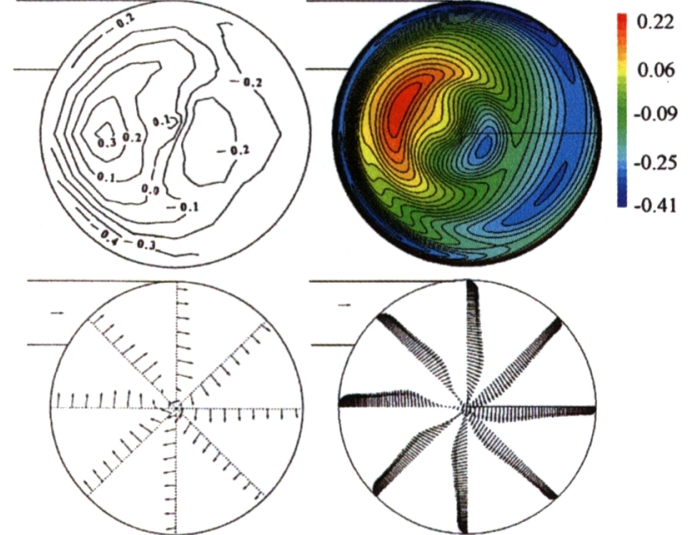

(a) Experiment

(b) LES

Fig.3 Mean velocity distribution in the $r-\theta$ plane at $z$ $=170 \mathrm{~mm}$ for TYPE-A, (a) experimental results ( $\left.r_{\mathrm{o}}=36 \mathrm{~mm}\right),(\mathrm{b})$ computational results

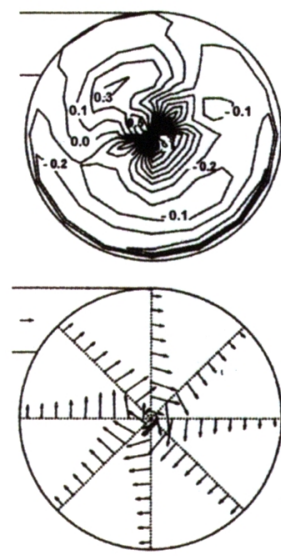

(a) Experiment
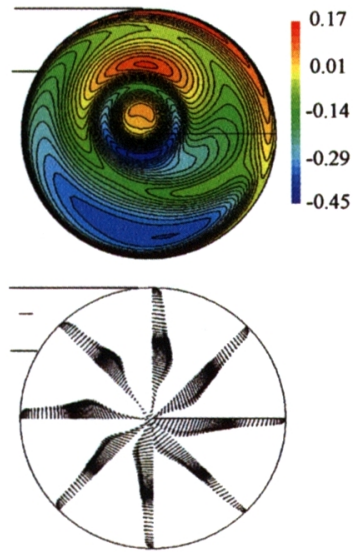

(b) LES
Fig.4 Mean velocity distribution in the $r-\theta$ plane at $z$ $=105 \mathrm{~mm}$ for TYPE-B, (a) experimental results $\left(r_{\mathrm{o}}=27 \mathrm{~mm}\right)$, (b) computational results

を与え, 圧力はノイマン条件とした. 流出境界では, 速度には Sommerfeld の放射条件を与え, 圧力は $r$ 方 向の運動方程式から Sommerfeld の方程式を差し引い て得られる圧力方程式より求めた ${ }^{(14)}$. 計算上の注意 事項として, 流出管の径 $\left(r_{0}=43.2 \mathrm{~mm}\right)$ をこれ以上小 さくして計算を行う場合, サイクロン中央付近の流速 が増大し, この領域で非常に複雑な流れ場が形成され, また，本計算では円筒座標系を用いているため, 管中 心付近の格子の異方性が大きいため, 計算が不安定に なることが確認されている. 更に小さい流出管の径の 計算を行う場合は，更に安定な時間スキーム(陰的な スキーム) や対流項スキームを適用し，流出管の長さ

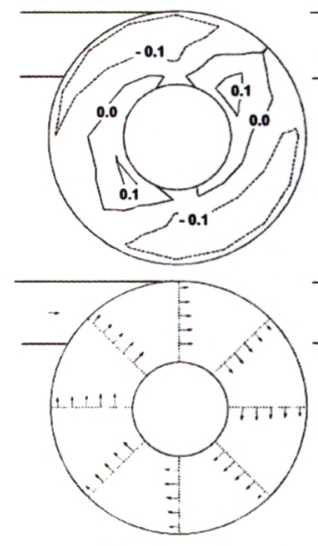

(a) Experiment
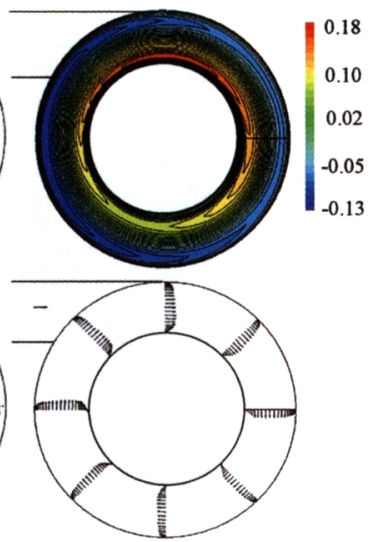

(b) LES

Fig.5 Mean velocity distribution in the $r-\theta$ plane at $z=20 \mathrm{~mm}$ for TYPE-B, (a) experimental results $\left(r_{o}=27 \mathrm{~mm}\right),(\mathrm{b})$ computational results

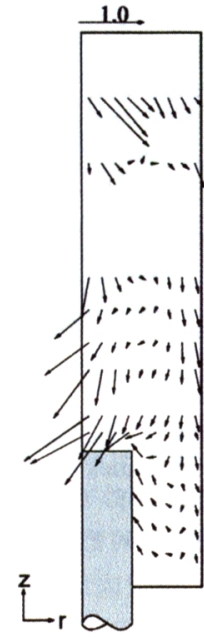

(a) Experiment

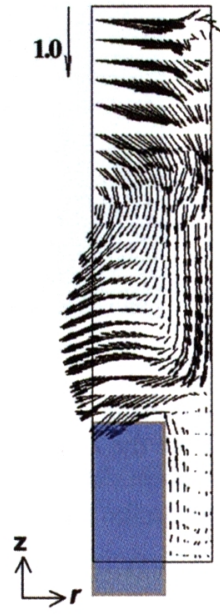

(b) LES
Fig.6 Mean velocity distribution in the $r-z$ plane at $\theta=150{ }^{\circ}$ for TYPE-B, (a) experimental results ( $\left.r_{\mathrm{o}}=27 \mathrm{~mm}\right),(\mathrm{b})$ computational results

も更に十分長くする必要がある. このことは今後の課 題である.

混入粒子には, 密度 $700 \mathrm{~kg} / \mathrm{m}^{3}$, 粒子径 5 および 10 $\mu \mathrm{m}$ のリコポジウム粒子を用い, 十分に発達した流 れ場中に 100,000 個の粒子が初期にサイクロン旋回室 上部の流入境界部にランダムに配置された. 流体と粒 子の運動は, One-way method に基づき同時に計算さ れる. 本計算では粒子の体積濃度が $O\left(10^{-9}\right)$ と非常に 希薄な状態であるので, 粒子間衝突は考慮しない. 壁 面と粒子が衝突する場合, 衝撃方程式を解くことによ 


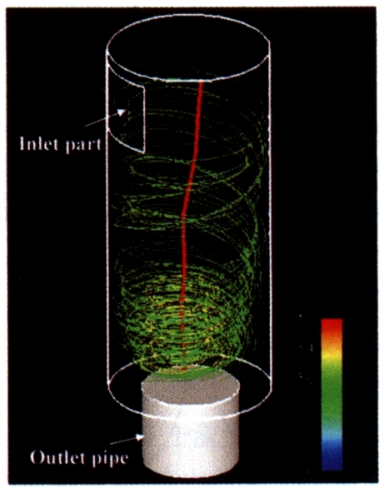

(a) TYPE-A

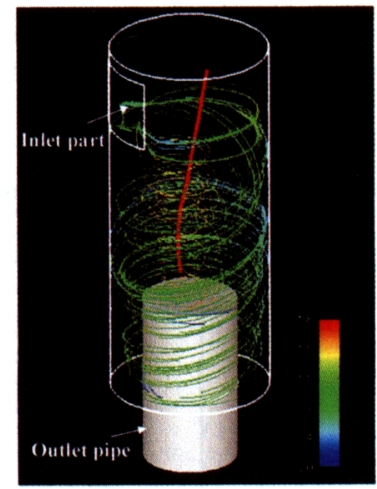

(b) TYPE-B

Fig.7 3-D mean flow field in the swirl chamber obtained from the LES; red bold lines display position of the vortex core, color of the streamlines corresponds to the magnitude of the velocity shown in the color bar

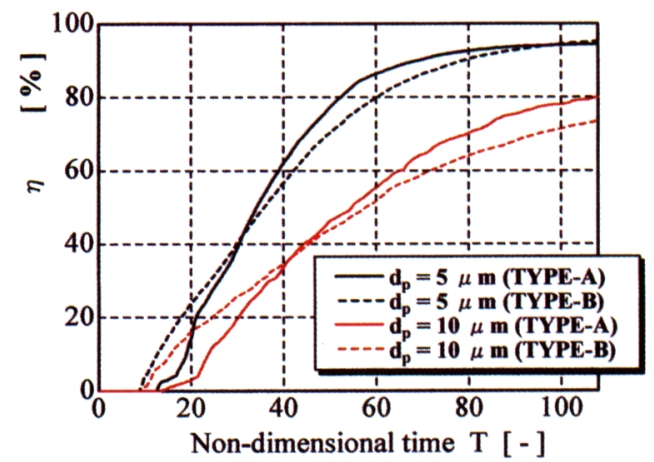

Fig.8 Time history of the collection rate of the particles

り, 衝突後の速度, 回転速度を算出した ${ }^{(12)}$. 表 2 に 今回用いた粒子の特性をまとめた。 なお, 表 2 中の反
発係数およひ摩摖係数は，粒子と壁面との衝突の衝撃 方程式を解く際に用いる。

\section{4. 計算結果および考察}

\section{4-1 平均流れ場の実験値との比較 図 3 に}

TYPE-A における $z=170 \mathrm{~mm}$ の位置の $r-\theta$ 断面の平均 流速分布を示寸，上図が軸方向速度の等高線図，下図 が速度べクトル図である. 実験結果は流出管半径が $36 \mathrm{~mm}$ に対寸るものである. この図から，全体的に実 験值と本計算結果はよく一致していることが分かる. 本計算の軸方向速度分布は，正負の值を示寸はっきり した 2つの領域を示している. これは，サイクロン内 旋回流れが螺旋渦構造を持っていることを示しており， この傾向は実験でも示されている. 速度ベクトル図を 見ると, 計算結果は実験結果と同様, ランキンの組合 せ渦形の速度分布を示していることが分かる．実験值 と計算值を比べると，流出管の大きさが若干違うため， 計算の強制渦領域は実験に比べわずかに大きくなって いることが分かる. 本計算の渦心は偏心しており, そ の程度は実験值よりも大きいことが確認できる.

図4に, TYPE-B における $z=105 \mathrm{~mm}$ の位置の図 3 と同様の平均速度分布を示寸. この参照断面は, 流出 管入口より $20 \mathrm{~mm}$ 上方に位置する. 比較に用いる実 験值は, 流出管半径が $27 \mathrm{~mm}$ の結果である. これら の図を見ると，計算結果と実験結果は定性的によい一 致を示していることが分かる. 実験と計算では流出管 の径が異なるため, 渦心の位置や軸方向, 周方向速度 の值に差異が見られるが，計算結果は，図 3 と同様， サイクロン内旋回流れの主要な特徴を十分に捉えてい ることが確認できる.

図 5 にTYPE-B における $z=20 \mathrm{~mm}$ の位置の平均速 度分布を示寸. 計算結果の軸方向速度を見ると, 軸方 向速度は流出管の近傍で正值を示し，旋回室の内壁近 くで負値を示す。この傾向は実験においても見られる. 速度ベクトルをみると, 半径方向にほとんど一様な回 転流れが碓認できる. これらの結果から，流出管外壁 と旋回室内壁の間の流れは一様な回転を伴って流出管 に沿って巻き上がっていることが分かる.このことは 図6に示寸 $r-z$ 断面の平均速度分布からも把握できる. この図から, 計算結果および実験結果両方とも, 明確 にその巻き上がりが確認できる. また，計算結果から 得られた流れパターンは，流出管の径が異なるため軸 方向速度が旋回室中心付近で小さくなるものの, 実験 結果と類似の傾向を示寸.

前述の議論から, 本研究における LES の結果は, 実験とは流出管の径が若干異なるため厳密な比較はで 


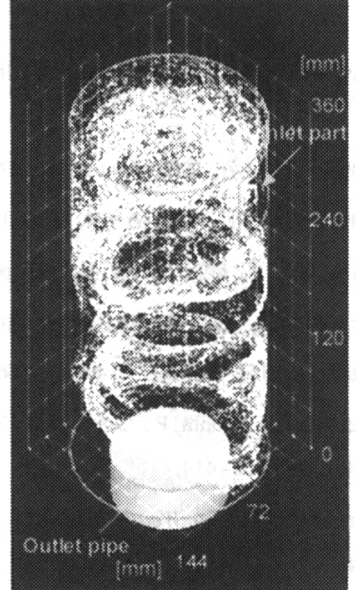

(a) $d_{p}=5 \mu \mathrm{m}$ (TYPE-A)

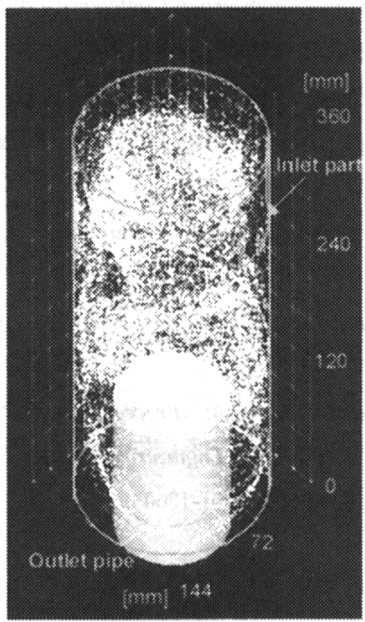

(b) $d_{p}=5 \mu \mathrm{m}$ (TYPE-B)

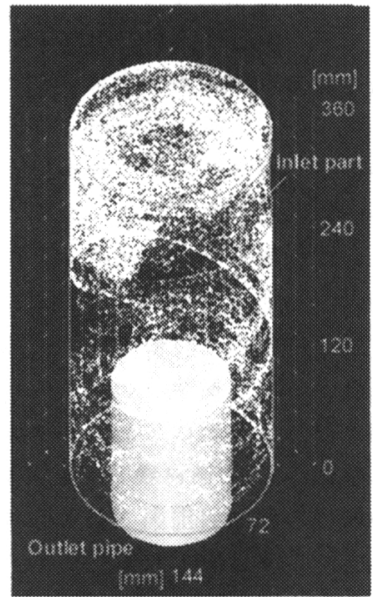

(c) $d_{p}=10 \mu \mathrm{m}$ (TYPE-B)

Fig.9 Instantaneous particle distributions at $T=20$
きないが，実験結果が示寸サイクロン分離器内旋回流 れの主要な特性を精度よく予測したものと考えられる.

図 7 に本研究の LES から得られた旋回室内の三次 元平均流九場の様子を示寸. 図中において, 赤の中心 線は渦心の位置を, 流線の色はカラーバーに相当する 流速の大きさを示寸. 流入方向は紙面に向から方向で ある.この図から, 旋回室内の流孔は三次元的な螺旋 渦を形成していることが分かる. 流入部近傍で渦心は 大きく偏心しており，その程度は TYPE-B の方が大 きい。

4.2 粒子分離性能の予測 ここでは, One-way method による粒子追跡の結果からサイクロン分離 器の粒子分離性能を試みた. 図 8 に TYPE-A, B の 粒子捕集率の時間履歴を示寸. 粒子捕集率は以下の 式で計算された.

$\eta=\frac{N_{\text {out }}}{N_{\text {total }}} \times 100$ [\%]

ここで， $N_{o u t}$ は流出管に捕集された粒子の個数, $N_{\text {total }}$ は旋回室内に混入された全粒子個数である. 縦 軸は捕集率，横軸が無次元時閒を示寸，この図を見る と，捕集率 $\eta$ は時間とともに指数的に増加しているこ とが分かる. 最終的には, TYPE-A では粒子径 5, 10 $\mu \mathrm{m}$ においてそれぞれ約 $90,80 \%$ 達成されることが分 かる. TYPE-Bでは，それぞれ約 90,70\%達成されて おり，TYPE-A の方がやや捕集率が高いことが分か る.これはおそらく, TYPE-B の多数の粒子は直接 流出管に捕集されないためであると考えられる.つま り，粒子は旋回室の底一落ちていき, 流出管外壁に沿 う巻き上がり流れによって上昇し, 流出管に捕集され る.このことは図9 (a), (b)に示寸 TYPE-A, B の瞬間 粒子分布の比較により分かる. 図 9 は無次元時間 20 （粒子を混入した時刻がゼロである）の結果である. また, 図9(b), (c)から, 粒子径 $5 \mu \mathrm{m}$ の粒子は旋回室 内に比較的一様に分布しているのに対して, $10 \mu \mathrm{m}$ の 粒子は旋回室上部に集積している. これは, サイクロ ン流入口付近でより大きな粒子が流体の遠心力の影響 によりの管壁側一移動し, 軸方向速度が減少したため だと考えられる. 換言すれば, 粒子の軸方向速度の減 少によりサイクロン旋回室の下部に位置寸る流出管一 の到達時間は長くなる. それゆえ，より小さい粒子の 捕集率は，大きい粒子のものより高いと考えられる.

本研究力゙提案寸る粒子追跡による粒子分離性能の予 測法は，実際の粒子数に比一非常に少ないものの，流 出管の挿入高さおよひ粒子径の違いに応じた粒子軌跡 を精度よくシミュレートでき, 粒子分離性能の簡易 
モデル構筑に大変有効であり, 高精度サイクロン分離 器の設計に大いに役立つと考えられる.

\section{5. 結}

本研究では, サイクロン分離器内の複雑な旋回流れ の乱流特性およびその乱流特性と粒子の挙動の関車性 を把握することを目的としている. 本報告では, 流出 管の挿入位置が異なる 2 種類のサイクロン分離器モデ ル（TYPE-A, B）の旋回流れ場の数值解析に LES の 適用を試みた. 加えて, 粒子の分離性能が, 個々の粒 子を One-way method に基づきラグランジュ的に追 う粒子追跡により見積もられた. その結果，本研究に おける LES の結果は, 実験結果が示寸旋回流れの主 要な特性を正確に予測しており，その有効性が確認さ れた. 粒子分離性能の予測の結果, TYPE-A の粒子 捕集率が TYPE-B のそれよりも高いことが分かった. これは, TYPE-B の多く粒子は旋回室底部に落ちて いき, 流出管外壁に沿う巻き上がり流れによって上昇 し，流出管に捕集されるためであると考えられる．ま た，本研究が提案する One-way method に基づいた 粒子追跡による分離性能の予測法は，流出管の挿入高 さおよひ粒子径の違いに応じた粒子の軌跡を精度よく シミュレートでき，粒子分離性能の簡易モデル構築に 大変有効であると考えられる.

続報では，格子解像度，SGS 応力モデル化などの 影響について報告する予定である.

\section{文献}

（1）松㥓和爱 - ほか 4名, 機埨，64-618，B(1998)，pp. 375380.

（2）松绮和愛・ほか4名，機論，64-618，B(1998)，pp.381-388.

（3）松绮和愛 - ほか3名, 機論, 66-641, B(2000), pp. 89-94.

（4）北村修・ほか3名, 機詥, 59-562, B(1993), pp. 1959-1964.

（5）北村修·山本誠，機論，60-580, B(1994), pp.4002-4009.

（6）小林敏雄 - 依田守生，機踰，52-481，B(1980), pp. 3230-3236.

(7) Verzicco, R. and Orlandi, P., Journal of Comput. Phys., 23 (1996), pp. 402- 414.

(8) Smagorinsky, J., Mon. Weath. Rev., 91 - 3 (1963), pp. $99-164$.

(9) Matsuzaki, K., et al., Proceedings of the 4th ASME/JSME Joint Fluids Engineerings Conference, (2003), FEDSM2003-45186.

（10）梶島 岳夫, 機論, 61-584, B (1995), pp. 1279 -1284.

(11) Maxey, M. R. and Riley J. J., Phys. Fluids, 26 (4) (1983), pp. 833 - 889.

(12) Yamamoto, Y., et al., J. Fluid Mech., 442 (2001), pp $303-334$

(13) Dennis, S. C. R., et al., J. Fluid Mech., 101, part 2 (1980), pp. 257-279.

(14) Matsuzaki, K., et al., Proceedings of ASME FEDSM'01 2001 ASME Fluids Engineering Division Summer Meeting, (2001), FEDSM2001-18003. 